\title{
Emerging design research practices
}

In the 1990s, early issues of arq were preoccupied with whether design could be research and, if so, how. A translation of Christopher Frayling's ideas from the field of fine art into architecture - thinking of research for architecture, by architecture, and through architecture - seemed reassuring at that time. Indeed, research through architecture appeared to offer an opportunity, encouraging 'Research where [...] the thinking is [...] embodied in the artefact, where the goal is not primarily communicable knowledge in the sense of verbal communication, but in the sense of visual or iconic or imagistic communication.' It made sense to architects that an artefact - a building or a drawing - could itself be research and not just the output of research, albeit not in every instance. In the intervening years, anxieties about the legitimacy of research by design have faded and the field is now booming, as evidenced by bulging bookshelves, blogs, and burgeoning PhD programmes.

Much contemporary design research is not conducted in mainstream architectural practices or in university schools but in studios located somewhere in-between. The time these researchers need to think - their 'laboratory time', as arq's first editor Peter Carolin called it - is often funded by a mix of university appointments, consultancy, studio teaching, and commercial projects. This issue of arq is focused on such emerging design research practices, as distinct from mainstream architectural practices. It has been curated by STASUS, led by James A. Craig and Matthew Ozga-Lawn, a firm whose research work has appeared in a variety of media including exhibitions, a volume of the Pamphlet Architecture series, speculative projects, and studios taught at various schools of architecture. Their 'perspective' (pp. 202-203) sets the contents of this issue in context.

STASUS's own paper (pp. 204-215) is prompted partly by questions over the hybrid nature of design research practices, especially their location, thinking of the studio as another site; as a proxy for the actual place of the project in the world and/or for embodied ways of designing. Ideas about representation and media connect the work of Kate Davies (pp. 205-211), Matthew Butcher (pp. 217-225), and Penelope Haralambidou (pp. 226-240). Papers from Bruno Gil (pp. 251-260), Luke Pearson (pp. 261-274), and Magnus Larsson, Alex Kaiser, and Ulf Arne Girhammar (pp. 275-286), meanwhile, explore relationships between 'the representational and the computational' in design. Elsewhere, Jan Kattein reflects on collaboration and the role of the 'Architect-Arbitrator' (pp. 287-297); and Jonathan Hill reviews the history of design research, understanding it as being (at least) 500 years old (pp. 241-250).

arq is pleased to present this lively selection of papers as an indication of the energy and commitment of emerging design research practices. We want to emphasise our openness to publishing work of this kind, alongside that from established academics and mainstream practitioners, and we look forward to including more in future.

THE EDITORS 